\title{
Germinação e crescimento in vitro de Cattleya bicolor Lindley (Orchidaceae)
}

\author{
Rogério Mamoru Suzuki ${ }^{1,5}$, Vanessa de Almeida ${ }^{2}$, Rosete Pescador $^{3}$ e Wagner de Melo Ferreira ${ }^{4}$
}

Recebido: 13.05.2010; aceito: 28.10 .2010

\begin{abstract}
In vitro germination and growth of Cattleya bicolor Lindley (Orchidaceae)). The technique of germinating orchid seeds in vitro has been used since the beginning of the last century. Nevertheless, the available knowledge regarding the nutritional composition of culture media that favor in vitro germination and growth of orchids is still scarce. Cattleya bicolor is a Brazilian threatened orchid species and very little is known about its seed germination and growth in vitro. For that reason, this study aimed at analyzing the influence of the culture medium on the in vitro germination of Cattleya bicolor seeds, on the initial development of its protocorms until they form seedlings, and on seedling growth during the first twelve months of in vitro culture. The results revealed that the Vacin \& Went is the ideal culture medium for seed germination and initial seedling development of Cattleya bicolor in vitro. It is recommended that after six months the seedlings be transferred to MS or VW media, since they promote seedling development. They should be kept in one of those media until acclimatization. These results are very important for the optimization of propagation techniques of Brazilian orchid species. Key words: asymbiotic germination, in vitro culture, media culture, orchid
\end{abstract}

RESUMO - (Germinação e crescimento in vitro de Cattleya bicolor Lindley (Orchidaceae)). A germinação de sementes de orquídeas in vitro vem sendo utilizada desde o início do século passado. Apesar disso, o conhecimento disponível a respeito da composição nutricional dos meios de cultura que favorecem a germinação e o crescimento in vitro de orquídeas ainda é bastante escasso. Diante da ameaça de extinção da Cattleya bicolor e devido à escassez de conhecimento a respeito da germinação e do crescimento in vitro dessa espécie, este trabalho teve como objetivo avaliar a influência do meio de cultura na germinação in vitro de suas sementes, no desenvolvimento inicial dos protocormos até a formação das plântulas, bem como avaliar o crescimento das plântulas até os primeiros doze meses de cultivo in vitro. Os resultados mostraram que o meio de cultura ideal para a germinação in vitro das sementes e para o desenvolvimento inicial das plântulas de Cattleya bicolor é o de Vacin \& Went. Recomenda-se que após seis meses de cultivo as plântulas sejam transferidas para o meio MS ou VW, que promovem o desenvolvimento das plântulas, e mantê-las em um destes meios de cultura até o início da aclimatização. Tais informações são de grande importância para a otimização do processo de propagação das espécies de orquídeas nativas do Brasil.

Palavras-chave: cultivo in vitro, germinação assimbiótica, meios de cultura, orquídea

\section{Introdução}

As técnicas de cultivo in vitro, nas últimas três décadas, têm sido amplamente utilizadas tanto para a propagação de orquídeas quanto para estudar aspectos fisiológicos relacionados ao desenvolvimento vegetal. A despeito de sua natureza herbácea, essas espécies apresentam crescimento bastante lento e, conseqüentemente, a produção de novas mudas é bastante demorada. As orquídeas permanecem no estado juvenil por longo período até atingir a maturação, podendo levar de 3 a 10 anos para florescerem (Ferreira \& Suzuki 2008). A germinação de sementes de orquídeas na natureza é dependente da simbiose com fungos específicos para cada espécie, e apenas cerca de 5\% germinam nestas

1. Instituto de Botânica, Núcleo de Pesquisa Orquidário do Estado, Av. Miguel Stéfano 3687, 04301-902 São Paulo, SP, Brasil

2. Orquidário Orquidácea, Estrada Municipal de Itapema, 4415 Caixa Postal 06, 08900-970 Guararema, SP, Brasil

3. Universidade Federal de Santa Catarina, Departamento de Fitotecnia, Rodovia Admar Gonzaga, Km 3, Itacorubi, 88034-001 Florianópolis, SC, Brasil

4. Universidade Federal do Tocantins, Núcleo de Estudos Ambientais (Neamb), Caixa Postal 111, 77500-000 Porto Nacional, TO, Brasil

5. Autor para correspondência: rogeriomsuzuki@yahoo.com.br 
condições (Stoutamire 1964). Por essas razões, as técnicas de cultivo in vitro tornaram-se bastante úteis para multiplicá-las mais rapidamente. Portanto, sob o ponto de vista preservacionista, a utilização dessa ferramenta é importante, pois possibilita a obtenção de um grande número de plantas em um tempo relativamente curto e com alta qualidade fitossanitária, contribuindo, dessa forma, para a diminuição do risco de extinção (Suzuki \& Ferreira 2007).

Além disso, vale a pena destacar que a cultura de tecidos é uma técnica de fundamental importância, tanto no melhoramento genético de plantas, como na obtenção de plantas sadias, sendo de grande interesse para a obtenção em larga escala de mudas geneticamente idênticas que darão origem à plantas com as características selecionadas e desejadas, fato este de grande relevância para a melhoria da produção das diferentes culturas, presentes na agricultura (Andrade 2002).

A germinação de sementes de orquídeas in vitro vem sendo realizada desde o início do século passado, quando Knudson em 1922 descreveu a germinação das mesmas em meio de cultura asséptico, na ausência de fungos. Por meio dessa técnica, sementes oriundas de plantas-matrizes adultas crescendo em ambiente natural ou em coleções vivas são utilizadas como fonte de propágulos. Embora a técnica seja utilizada há quase um século e vários pesquisadores tenham recorrido à germinação in vitro para multiplicar espécies de orquídeas (Rasmussen 1995, Shiau et al. 2005, Stewart \& Kane 2006), o conhecimento disponível a respeito da composição nutricional que favorece a germinação e o crescimento in vitro de orquídeas ainda é bastante escasso. Os meios de Knudson (1946), Vacin \& Went (1949) e Murashige \& Skoog (1962) são alguns dos mais utilizados no cultivo in vitro.

Cattleya bicolor Lindley é uma espécie endêmica do Brasil, e de acordo com Braem (1984) possui como características: presença de pseudobulbos finos, com pouco tecido de estocagem de água, duas folhas oblongo-lanceoladas, como outras catléias bifoliadas e flores com pétalas espessas e espatuladas. A inflorescência possui de duas a dez flores perfumadas, uniformemente brilhantes e a coloração varia de verde pálido ou oliva a uma tonalidade cobremarrom, podendo apresentar pintas verde-marrom. O labelo consiste de um lobo simples, sendo esta característica dominante e transmitida a sua progênie, tornando pelo menos parte do parentesco nitidamente detectável; sua coloração varia do vermelho a rosa, algumas vezes emergindo da extremidade a cor branca. Devido às características de coloração e estrutura, o labelo parece exibir uma aparência de textura aveludada.

A beleza de suas flores pode ter impulsionado a sua procura na natureza. Além disso, o ciclo de vida altamente especializado das orquídeas e a crescente destruição das florestas, tanto para expansão agropecuária quanto para o avanço da área urbana das cidades (Ferreira \& Suzuki 2008), possivelmente contribuíram para a inclusão da Cattleya bicolor na categoria de espécie da flora vulnerável à extinção no Estado de São Paulo (Barros 2007).

Diante da ameaça de extinção desta espécie de orquídea e a escassez de conhecimento a respeito de sua germinação e crescimento in vitro, este trabalho teve como objetivo avaliar a influência do meio de cultura na germinação in vitro de sementes e no desenvolvimento inicial dos protocormos de Cattleya bicolor até a formação das plântulas, bem como analisar o crescimento dessas plântulas após o primeiro ano de cultivo in vitro.

\section{Material e métodos}

O experimento foi realizado no laboratório de cultivo in vitro do Núcleo de Pesquisa Orquidário do Estado. Foram utilizadas como material de estudo plantas de $C$. bicolor selecionadas previamente para polinização cruzada, pertencentes à coleção científica "Frederico Carlos Hoehne" do referido núcleo do Instituto de Botânica de São Paulo.

As sementes foram retiradas de frutos maduros, ou seja, oito meses após a polinização das flores, e armazenadas a $4^{\circ} \mathrm{C}$, durante cerca de $24 \mathrm{~h}$ para a semeadura in vitro. As sementes foram embebidas em água destilada durante 30 minutos e a desinfestação foi realizada por meio da imersão das sementes em solução de $15 \%$ (v/v) de hipoclorito de sódio comercial (2\%-2,5\% de cloro ativo) durante dez minutos, sob constante agitação. Em seguida, com o auxílio de uma micropipeta e ponteiras esterilizadas, a solução de hipoclorito foi retirada e as sementes lavadas três vezes em água destilada e esterilizada. Foram então inoculadas em três meios de cultura: o meio VW Vacin \& Went (1949), modificado pela substituição do $\mathrm{Fe}_{2}\left(\mathrm{C}_{4} \mathrm{H}_{4} \mathrm{O}_{6}\right)_{3}$ pelo Fe-EDTA, o meio Murashige \& Skoog (1962) e o meio de KC Knudson C (1946) (tabela 1), todos suplementados com $2 \%$ de sacarose e micronutrientes do meio MS, e geleificados com $0,4 \%$ de ágar bacteriológico. O 
Tabela 1. Composição dos nutrientes dos meios de cultura utilizados para a germinação assimbiótica de sementes, desenvolvimento inicial e crescimento de plântulas de Cattleya bicolor e comparação com o meio P723.

Table 1. Macronutrient composition of germination media used for the asymbiotic seed germination, early development, and seedlings growth of Cattleya bicolor, and comparison with P723 media.

\begin{tabular}{|c|c|c|c|c|}
\hline Nutrientes & $\begin{array}{l}\text { Knudson C } \\
\qquad(1946) \\
(\mathrm{KC}) \mathrm{mM}\end{array}$ & $\begin{array}{l}\text { Murashige \& } \\
\text { Skoog (1962) } \\
\text { (MS) mM }\end{array}$ & $\begin{array}{c}\text { Vacin \& } \\
\text { Went (1949) } \\
(\mathrm{VW}) \mathrm{mM}\end{array}$ & $\begin{array}{l}\text { P723 } \\
\text { PhytoTechnology Orchid } \\
\text { Seed Sowing Medium mM }\end{array}$ \\
\hline Amônia $\left(\mathrm{NH}_{4}^{+}\right)$ & 7,57 & 20,62 & 7,57 & 5,15 \\
\hline Nitrato $\left(\mathrm{NO}_{3}^{-}\right)$ & 8,47 & 39,43 & 5,20 & 9,85 \\
\hline Fosfato $\left(\mathrm{PO}_{4}^{---}\right)$ & 1,84 & 1,25 & 3,13 & 0,31 \\
\hline Potássio (K) & 1,84 & 20,06 & 6,97 & 5,62 \\
\hline Sulfato $\left(\mathrm{SO}_{4}^{---}\right)$ & 4,84 & 1,50 & 4,90 & 0,71 \\
\hline Cálcio $\left(\mathrm{Ca}^{++}\right)$ & 4,24 & 3,01 & 1,93 & 0,75 \\
\hline Magnésio $\left(\mathrm{Mg}^{++}\right)$ & 1,02 & 1,50 & 1,02 & 0,62 \\
\hline Cloro $\left(\mathrm{Cl}^{-}\right)$ & - & 6,03 & - & 1,50 \\
\hline Nitrogênio total & 16,04 & 60,06 & 12,77 & 15,00 \\
\hline Relação $\mathrm{NH}_{4}^{+}: \mathrm{NO}_{3}^{-}$ & 0,89 & 0,52 & 1,46 & 0,52 \\
\hline
\end{tabular}

sulfato de manganês foi adicionado separadamente ao meio $\mathrm{KC}$ devido à menor concentração desse micronutriente na composição desse meio de cultura. Todos os componentes utilizados possuíam grau de pureza para análise (P.A.).

$\mathrm{O} \mathrm{pH}$ dos meios de cultura foi ajustado para 5,8 $\pm 0,05$, anteriormente à adição de $0,4 \%$ de ágar. Após a homogeneização, foram distribuídos em frascos de vidro de $200 \mathrm{~mL}$, sendo que em cada frasco foram colocados $40 \mathrm{~mL}$ de meio de cultura. A esterilização dos meios foi realizada em autoclave a $120^{\circ} \mathrm{C}$ e 1,3 atm durante 15 minutos.

O delineamento experimental utilizado foi o inteiramente casualizado, constando de três tratamentos (meios de cultura), representados por repetições (três frascos de cultivo) para cada tratamento, os quais foram mantidos em sala de cultura com temperatura média de $25 \pm 2{ }^{\circ} \mathrm{C}$, fotoperíodo de 12 horas e intensidade luminosa de aproximadamente $20 \mu \mathrm{mol} \mathrm{m} \mathrm{m}^{-2} \mathrm{~s}^{-1}$ obtida com lâmpadas fluorescentes.

Vinte e cinco dias após a inoculação das sementes foi realizada a análise da taxa de germinação (germinabilidade), obtendo-se a percentagem de sementes germinadas e não germinadas, a partir da retirada de três amostras de cada um dos frascos dos diferentes meios de cultura, realizada por meio da adição de $3 \mathrm{~mL}$ de água esterilizada, posterior homogenização e coleta de três amostras de $1 \mathrm{~mL}$ contendo as sementes para análise.
Cada amostra foi depositada sobre uma lâmina quadriculada e todas foram analisadas em estereomicroscópio, totalizando aproximadamente 3.500 sementes para cada tratamento. Foram consideradas germinadas as sementes com embrião intumescido e clorofilado, características do estádio de protocormo nas orquídeas. Os dados referentes à percentagem foram transformados em $\operatorname{arcsen}(\mathrm{x}+$ $10)^{1 / 2}$ e submetidos à análise de variância (ANOVA), seguido do teste de separação das médias de Tukey em nível de 5\% de significância.

Após 120 e 180 dias da inoculação das sementes, cerca de 500 protocormos de cada tratamento (aproximadamente 170 protocormos de cada frasco), foram retirados e avaliados quanto às diferentes fases do desenvolvimento inicial. Esse método foi o mesmo utilizado por Suzuki et al. (2009), sendo considerados quatro estádios distintos de desenvolvimento: a) estádio 1 = protocormo intumescido clorofilado, b) estádio 2 protocormo com formação da primeira folha, c) estádio 3 = protocormo com duas ou mais folhas, d) estágio 4 = plântula com folhas e uma ou mais raízes.

Para o estudo sobre o crescimento inicial das plantas, foram utilizadas plantas com 180 dias de cultivo após a inoculação das sementes, que possuíam o mesmo comprimento $(1 \pm 0,2 \mathrm{~cm}$ de altura, medida da base do caule até a extremidade da folha maior). Estas plantas foram transferidas 
para frascos de cultura de $400 \mathrm{~mL}$ contendo $80 \mathrm{~mL}$ de meio para cada tratamento (os meios VW, MS e $\mathrm{KC}$ ), e mantidas nas mesmas condições ambientais citadas anteriormente. Para cada tratamento foram utilizados três frascos (repetições) contendo quinze plântulas. Ao final de mais seis meses de cultivo quarenta plantas de cada tratamento foram retiradas aleatoriamente e analisadas em relação ao número médio de folhas e raízes formadas, quanto ao comprimento caulinar médio, sendo considerada a medida da base do caule até a extremidade da maior folha, comprimento médio da maior raiz, além da média das massas de matéria fresca e seca das porções caulinar e radicial, separadamente. A massa de matéria seca foi mensurada após os caules e raízes terem sido mantidos em estufa a $60^{\circ} \mathrm{C}$, até a obtenção de massa constante.

Para cada parâmetro de crescimento analisado foi realizado tratamento estatístico a partir da análise de variância (ANOVA), seguido do teste de separação das médias utilizando-se o teste de Tukey em nível de 5\% de significância.

\section{Resultados e Discussão}

O início da germinação das sementes de $C$. bicolor foi verificado cerca de quinze dias após a inoculação das mesmas nos diferentes meios de cultura. Neste trabalho a contaminação foi $5,5 \%$. Os resultados da germinabilidade foram apresentados na tabela 2. O maior percentual de germinação foi verificado no meio VW (66,8\%), enquanto que no MS foi de $60,8 \%$ e no $\mathrm{KC}$ de $48,5 \%$. Tais resultados foram diferentes daqueles encontrados por Suzuki et al. (2009) para Hadrolaelia tenebrosa e Kohl (1962) para diferentes espécies de Cymbidium que observaram maior germinação nos meios KC. Isso mostra que as respostas germinativas podem variar consideravelmente entre diferentes gêneros e até mesmo entre espécies de um mesmo gênero.

No trabalho de Dutra et al. (2008) ao estudar a influência de diferentes fotoperíodos, meios de cultura, incluindo $\mathrm{KC}$, VW e $1 / 2 \mathrm{MS}$ (MS reduzido à metade da concentração de nutrientes), e geleificação ou não destes meios, na germinação e crescimento inicial de Bletia purpurea verificaram que não houve diferença significativa em termos de germinabilidade a qual variou de $96,3 \%$ a $100 \%$ nos diferentes tratamentos utilizados. Para Cyrtopodium punctatum, Dutra et al. (2009) utilizando os mesmos tratamentos do trabalho anterior, observaram que o VW foi um dos meios de cultura que proporcionou a maior percentagem de germinação, cujo valor foi de $26,1 \%$, quando comparados aos meios $1 / 2 \mathrm{MS}$ e $\mathrm{KC}$, com percentuais de germinação de $12,1 \%$ e $10 \%$, respectivamente.

A maior percentagem de germinação de sementes observada em $C$. bicolor no meio VW fortalece a proposta de Gamborg (1970) de que a presença de amônia é mais eficiente na germinação de sementes de orquídeas do que o nitrato, pois VW é o meio que apresenta a maior relação amônia:nitrato $(1,46)$, quando comparada a dos meios $\mathrm{KC}$ e MS cujos valores são de 0,89 e 0,52 respectivamente (tabela 1). Os resultados aqui apresentados também estão em consonância com aqueles apresentados por Ichihashi e Yamashita (1977), que verificaram que sementes de Bletilla striata têm preferência por baixas concentrações de nitrogênio inorgânico e pela forma reduzida amônia $\left(\mathrm{NH}^{+}\right)$, e pelos detectados por Rasmussen (1995) em Dactylorhiza majalis, que observou uma redução na percentagem de germinação das sementes desta espécie quando se aumentava a concentração de nitrato no meio de cultura. Mais recentemente, Kauth et al. (2006), observaram em Calopogon tuberosus que os meios de cultura com

Tabela 2. Germinabilidade média de sementes de Cattleya bicolor obtida vinte e cinco dias após a semeadura in vitro. Letras diferentes apresentam variação significativa entre os tratamentos, segundo teste de Tukey $(\mathrm{P}<0,05)(\mathrm{n}=3500)$.

Table 2. Seed germination average percentage of Cattleya bicolor twenty and five days after in vitro sowing. Different letters are significantly different, according to the Tukey test $(\mathrm{P}<0,05)$. $(\mathrm{n}=3500)$.

\begin{tabular}{ll}
\hline Meios de cultura & Germinabilidade (\%) \\
\hline KC - Knudson & $48,5 \mathrm{~b}$ \\
MS - Murashige \& Skoog & $60,8 \mathrm{ab}$ \\
VW - Vacin \& Went & $66,8 \mathrm{a}$ \\
\hline
\end{tabular}


maior proporção de amônia em relação ao nitrato são mais eficazes para a germinação das sementes desta espécie de orquídea.

Todos estes resultados evidenciam que a escolha do meio de cultura é extremamente importante para o sucesso da germinação de sementes de orquídeas (Suzuki et al. 2009). Além disso, as respostas germinativas possivelmente variam de uma espécie para outra, não havendo outra opção senão a de estudar a melhor composição nutricional para cada espécie, principalmente àquelas ameaçadas de extinção, com a finalidade de proporcionar a multiplicação de um maior número de plantas e deste modo garantir a conservação das espécies.

Os resultados do experimento sobre o desenvolvimento inicial dos protocormos após 120 dias de semeadura in vitro, nos diferentes meios de cultura são mostrados na figura 1A. É possível notar que aproximadamente $50 \%$ dos protocormos no meio $\mathrm{KC}$ encontravam-se no estádio 2 , enquanto que $31,7 \%$ estavam no primeiro estádio e $18,3 \%$ no terceiro estádio. Com relação às sementes inoculadas no meio MS, 39,7\% dos protocormos permaneceu no primeiro estádio de desenvolvimento, sendo que os estádios 2 e 3 representaram respectivamente $38,8 \%$ e $21,5 \%$ dos protocormos em desenvolvimento. No meio VW $38,8 \%$ dos protocormos estavam no estádio 2 , e $37,1 \%$ e $23,5 \%$ representaram os estádios 1 e 3 respectivamente.

A análise de desenvolvimento inicial realizada após sete semanas por Stewart \& Kane (2006) em sementes de Habenaria macroceratitis, mostrou que no meio VW havia maior proporção de plântulas, ou seja, em estádios mais avançados do processo de desenvolvimento dos protocormos comparativamente aos meios KC e MS. Resultados semelhantes para o meio VW foram encontrados por Suzuki et al. (2009) estudando a germinação de sementes e o desenvolvimento de plantas de H. tenebrosa. Em C. bicolor, aos quatro meses de cultura, nenhum meio de cultura promoveu de forma acentuada o desenvolvimento, embora os meios $\mathrm{KC}$ e VW tenham sido mais eficazes favorecendo uma maior percentagem de protocormos nos estádios $2 \mathrm{e}$ 3 (figura 1A).

Os resultados do desenvolvimento inicial dos protocormos, decorridos 180 dias da semeadura in vitro, são mostrados na figura $1 \mathrm{~B}$. $\mathrm{O}$ meio $\mathrm{KC}$ apresentou protocormos e plantas em todas as fases de desenvolvimento, sendo que a maior parte $(69,9 \%)$ no estádio 4. No meio MS, os protocormos apresentaram distribuição semelhante entre os estádios 2, 3 e 4, respectivamente 32,$8 ; 30,6 \%$ e $26,2 \%$. No meio VW, as plântulas $(97,1 \%)$ estavam em maior percentagem no estádio 4. Comparando-se com os outros meios de cultura testados, o VW apresentou-se com percentagem de plântulas no estádio 4 bastante superior aos demais, demonstrando que este meio estimula de forma mais eficaz o desenvolvimento das plântulas, logo após a germinação das sementes.

Dutra et al. (2008) verificaram que plântulas de Bletia purpurea cultivadas in vitro atingiram o estádio de plântula com duas folhas mais rapidamente quando as sementes foram inoculadas no meio VW. Por outro lado, Dutra et al. (2009) observaram que em Cyrtopodium punctatum, o estádio mais avançado (plântulas com folhas) e a promoção do alongamento caulinar, foram obtidos nos meios P723 (tabela 1) e $1 / 2 \mathrm{MS}$. Enquanto o meio VW apresentou plântulas com dois primórdios foliares (estádio menos desenvolvido), no meio $\mathrm{KC}$ não foi sequer observado a formação de plântulas. O maior percentual de plântulas de $C$. bicolor com folhas e raízes (estádio 4) aos seis meses no meio VW $(97,1 \%)$ foi superior à verificada em outra espécie epífita presente na Mata Atlântica, H. tenebrosa, em que a maior percentagem se encontrava no estádio $3(77 \%)$ e o restante $(23 \%)$ no estágio 4 (Suzuki et al. 2009). Esta diferença entre as duas espécies se deve ao crescimento mais rápido das plantas de C. bicolor, quando comparadas àquelas de H. tenebrosa. Diferentemente, os estudos realizados por Stewart \& Kane (2006), mostraram que o meio MS foi o que proporcionou o desenvolvimento mais rápido dos protocormos de Habenaria macroceratitis quando comparado aos outros meios.

Muitos pesquisadores relatam que a presença de nitrogênio inorgânico no meio de cultura pode limitar a germinação e o desenvolvimento inicial de plântulas, possivelmente porque algumas espécies de orquídeas inicialmente são deficientes das enzimas associadas ao metabolismo do nitrogênio, como por exemplo, a nitrato redutase, impedindo, desta forma que utilizem o nitrato presente no meio de cultura (Raghavan \& Torrey 1964, Van Waes \& Debergh 1986, Rasmussen 1995).

No caso de C. bicolor, a germinação das sementes e o desenvolvimento pós-germinativo das plântulas nos meios de cultura testados, podem indicar que esta espécie possui capacidade de produzir precocemente as enzimas necessárias para a assimilação do nitrogênio, ou ainda que a concentração de amônia nos meios utilizados seja adequada para a germinação 


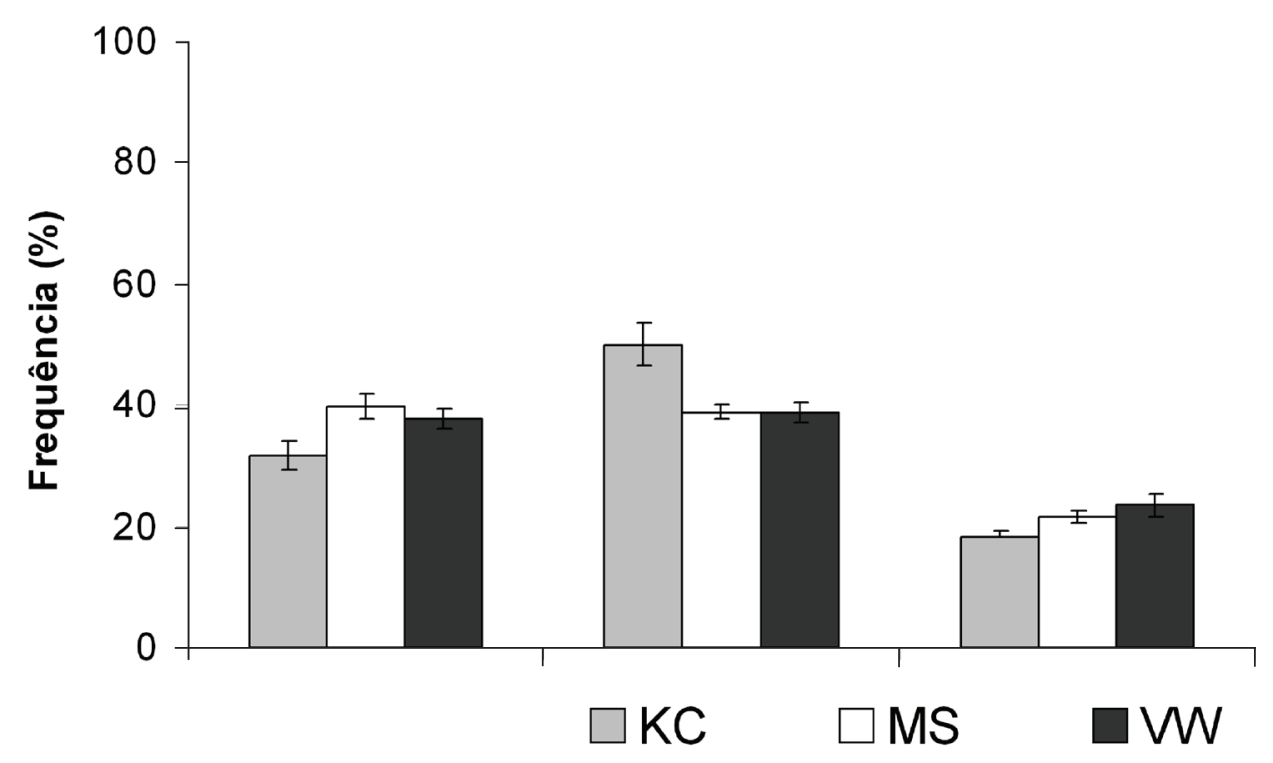

A

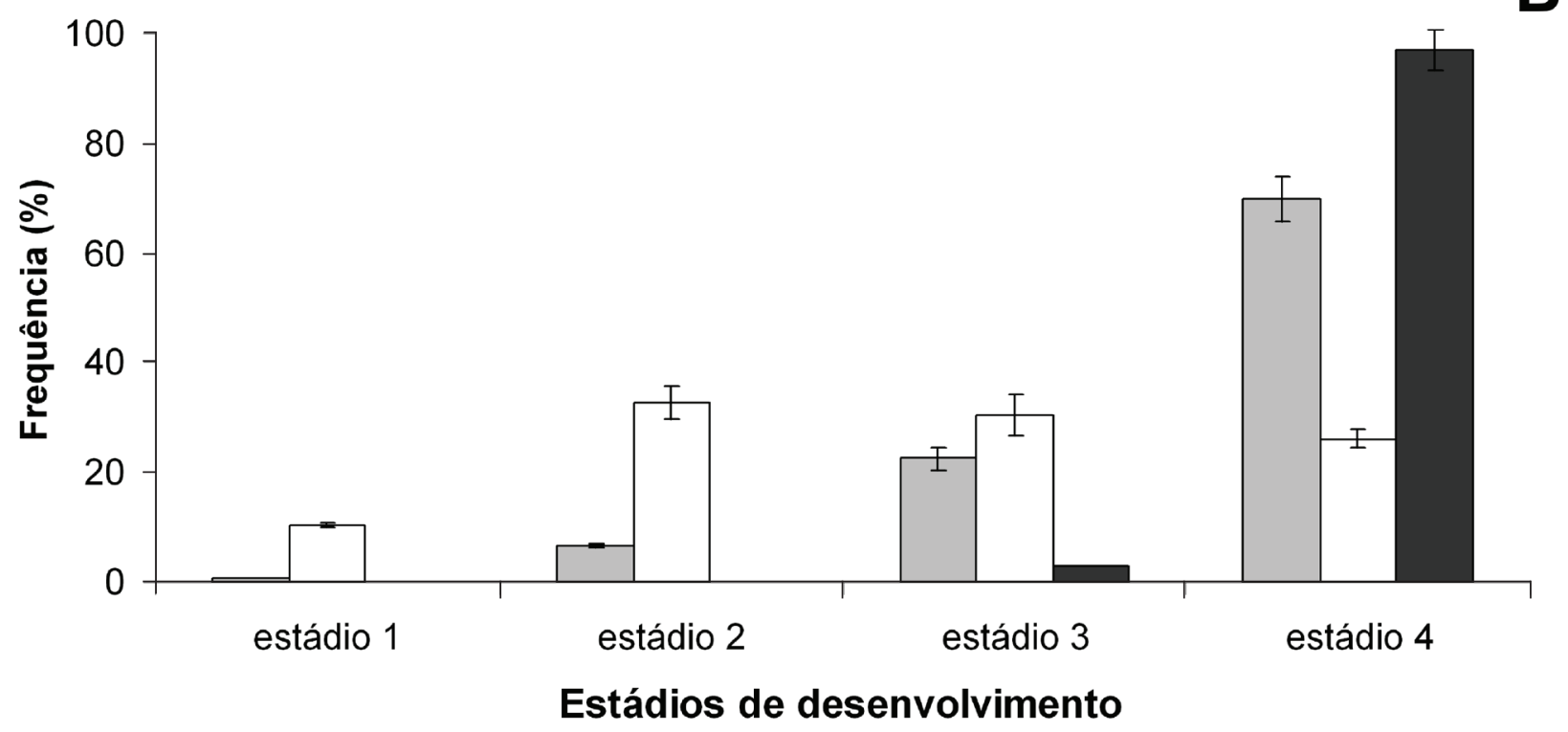

Figura 1. Efeitos de diferentes meios de cultura no desenvolvimento inicial de protocormos de Cattleya bicolor A) cento e vinte dias após a semeadura in vitro e B) cento e oitenta dias após a semeadura in vitro. Estádio $1=$ protocormo intumescido clorofilado, estádio 2 = protocormo com formação da primeira folha, estádio 3 = protocormo com duas ou mais folhas, estádio $4=$ plântula com folhas e uma ou mais raízes. $(n=500)$

Figure 1. Effects of different culture media on the initial development of Cattleya bicolor protocorms. (A) 120 and (B) 180 days after in vitro seed inoculation. Stage $1=$ chlorophylled swelled protocorm, stage 2 = protocorm exhibiting the first leaf, stage $3=$ protocorm with two or more leaves, stage $4=$ seedling with leaves and one or more roots. $(n=500)$ 
e o desenvolvimento posterior das plântulas, até que sejam capazes de assimilar o nitrogênio na forma de nitrato. Interessantemente, os meios VW e $\mathrm{KC}$ que apresentaram maior percentagem de plântulas no estádio 4 , possuem também a maior relação de amônia:nitrato, comparativamente ao meio MS (tabela 1, figura 1B). Além disso, ambos não possuem cloro, apresentam menor concentração de nitrogênio e maior concentração de sulfato em sua composição, comparativamente ao meio MS (tabela 1).

Aanálise conjunta sobre agerminação de sementes e o estudo do desenvolvimento inicial mostrou que o meio de cultura que promoveu de maneira mais eficaz estes dois processos foi o meio VW. É possível que por se tratar de uma espécie epífita que habita naturalmente locais com disponibilidade limitada de recursos o meio VW tenha favorecido melhores respostas exatamente por ser aquele com menores concentrações de macronutrientes. É possível que elevadas concentrações de macronutrientes causem toxidez à C. bicolor .

Após seis meses de cultivo, verificou-se que o comprimento do caule foi significativamente maior em plantas incubadas no meio VW $(2,3 \mathrm{~cm})$, seguido do meio $\mathrm{KC}(2,1 \mathrm{~cm})$ e do meio MS $(1,8$ $\mathrm{cm})$, conforme pode ser verificado na figura $2 \mathrm{~A}$. Em relação ao crescimento das raízes, observouse que as plantas cultivadas no meio $\mathrm{KC}$ possuíam raízes de $2,4 \mathrm{~cm}$ significativamente superiores ao comprimento verificado nos demais tratamentos, MS e VW, cujos valores encontrados foram de $2,1 \mathrm{~cm} \mathrm{e}$ $1,9 \mathrm{~cm}$, respectivamente.

Estes resultados são bastante contrastantes aos obtidos por outros autores com outras espécies de orquídeas em relação ao comprimento de caules e raízes. Ferreira (2003) não encontrou diferenças significativas entre os meios MS e VW para o crescimento caulinar de Dendrobium Second Love. Rego-Oliveira \& Faria (2005) verificaram em Catasetum fimbriatum que o meio MS promoveu o crescimento caulinar e radicial, em relação aos meios KC e VW; em Cyrtopodium paranaensis o comprimento do caule também foi promovido quando as plantas foram incubadas no meio MS, entretanto o tamanho das raízes foi estimulado no meio KC. Suzuki et al. (2009) não observaram diferenças significativas entre esses mesmos meios de cultura para o parâmetro comprimento caulinar, mas o crescimento das raízes foi significativamente estimulado no meio VW.

Analisando-se os resultados apresentados na figura 2B é possível verificar que o meio MS foi o mais eficiente para a produção de folhas em C. bicolor do que o meio $\operatorname{KC~}(8,1$ e 7,4 folhas, respectivamente). Com relação às raízes, não foram observadas diferenças significativas entre os meios de cultura utilizados, o número de raízes variou entre 4 (KC) e 4,4 (MS e VW). Suzuki et al. (2009) observaram que em plantas de H. tenebrosa os meios MS e VW foram os que proporcionaram a produção de um maior número de folhas $(6,7$ e 6,1 , respectivamente), enquanto que a formação de raízes foi mais eficaz no meio VW. Rego-Oliveira \& Faria (2005) observaram maior quantidade de raízes em Catasetum fimbriatum no meio MS, enquanto que em Cyrtopodium paranaensis o maior número de raízes foi obtido no meio $\mathrm{KC}$.

No que diz respeito à massa da matéria fresca dos caules, observou-se que o meio MS foi significativamente favorável $(76,6 \mathrm{mg})$ seguido pelos meios VW (73,3 mg) e KC (57,1 mg). Por sua vez, as raízes apresentaram massa fresca maior em plântulas cultivadas sob o meio VW $(49,6 \mathrm{mg})$, seguida do meio MS (42,6 mg). O meio KC produziu raízes de menor matéria fresca $(38,1 \mathrm{mg})$. Os resultados obtidos para a massa de matéria seca das plantas de $C$. bicolor após 180 dias de cultivo in vitro (figura 3B) mostraram que os caules apresentaram significativamente maior matéria seca nos meios MS (5,4 mg) e VW $(5,8$ $\mathrm{mg})$ comparativamente ao meio $\mathrm{KC}(4,6 \mathrm{mg})$. Para as raízes, o meio $\mathrm{MS}$ (4,2 $\mathrm{mg}$ ) foi o que promoveu significativamente o maior acúmulo de matéria seca em relação aos meios KC (3,5 mg) e VW (3,7 mg).

Rego-Oliveira \& Faria (2005), estudando o cultivo in vitro de Cyrtopodium paranaensis, também detectaram que o meio MS foi o mais favorável para o acúmulo de matéria seca caulinar. Entretanto, em Catasetum fimbriatum o melhor resultado foi observado no meio KC. No que diz respeito à massa seca radicial, esses autores verificaram que o meio VW e o MS foram os mais favoráveis para Cyrtopodium paranaensis e Catasetum fimbriatum, respectivamente. No caso da espécie $H$. tenebrosa, Suzuki et al. (2009) observaram que o maior acúmulo de matéria seca caulinar ocorreu no meio MS, enquanto que o VW favoreceu significativamente o acúmulo de massa de matéria seca das raízes, sendo que para este último parâmetro o meio MS foi extremamente inibitório.

Para melhor entender os resultados apresentados em relação ao crescimento inicial das plantas de C. bicolor nas condições do presente estudo, é 

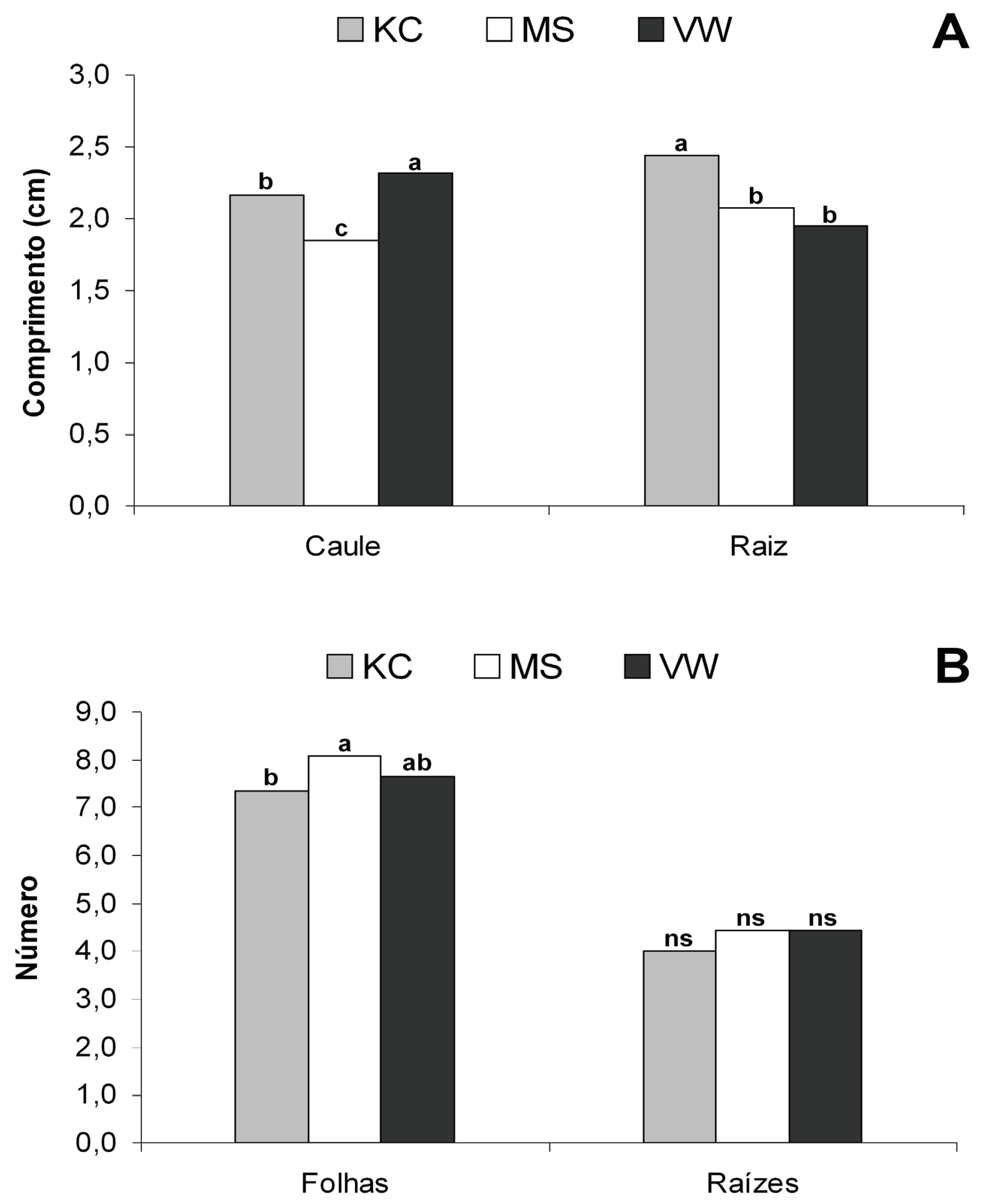

Figura 2. Efeitos de diferentes meios de cultura no comprimento médio de caules e da raiz maior (A) e no número de folhas e raízes (B) de Cattleya bicolor após 180 dias de cultivo in vitro. Barras seguidas de letras diferentes apresentam variação significativa entre os tratamentos, segundo teste de Tukey $(\mathrm{P}<0,05)$. Barras seguidas de "ns" não apresentaram variação significativa entre os tratamentos. (n $=40)$.

Figure 2. Effects of different culture media on average of shoot and longest root length (A) and on the number of leaves and roots (B) of Cattleya bicolor after 180 days of in vitro culture. Vertical bars with different letters are significantly different, according to the Tukey (P $<0.05)$. Vertical bars with "ns" did not show significant variation between treatments. $(n=40)$. 

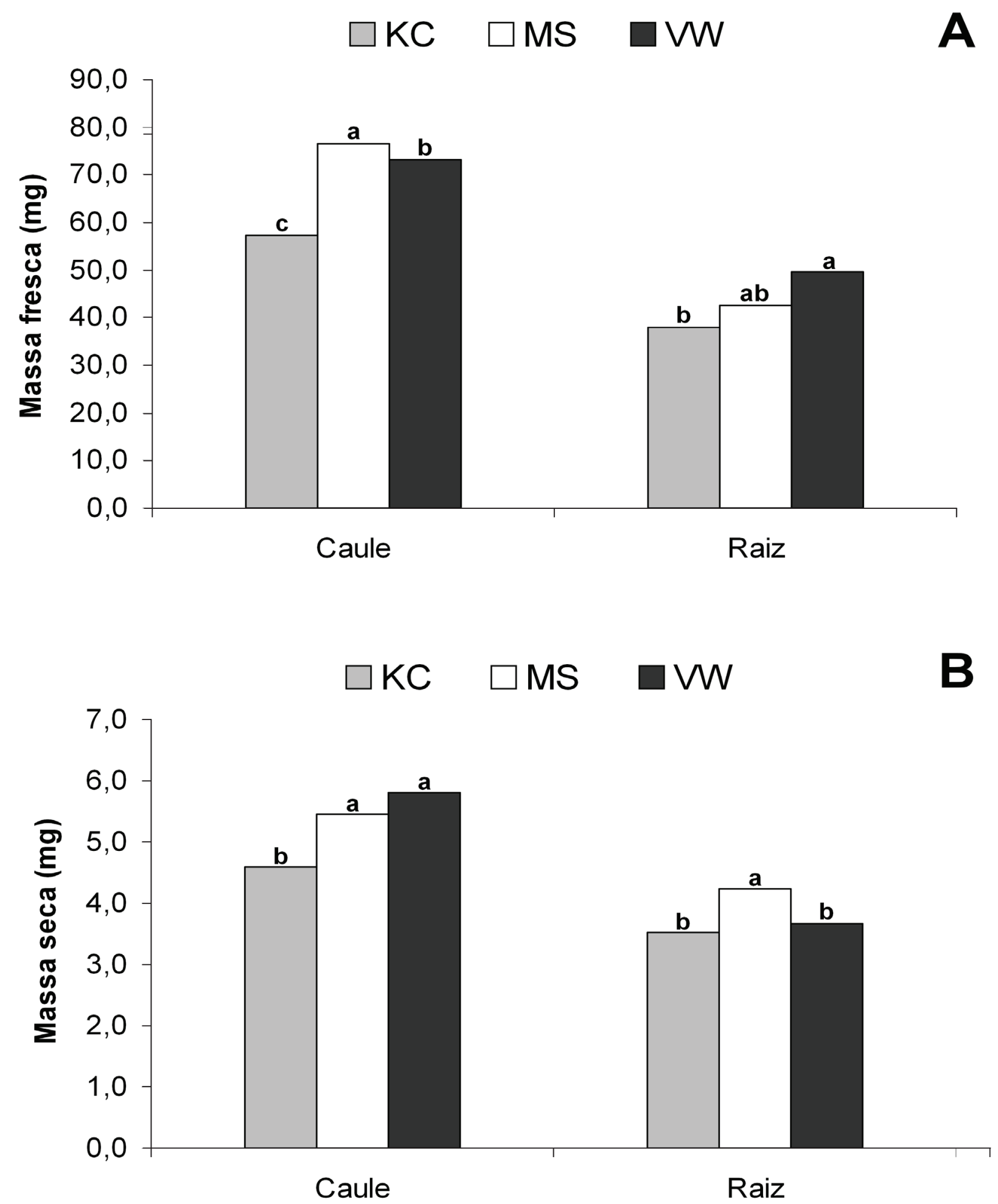

Figura 3. Efeitos de diferentes meios de cultura sobre o acúmulo médio da massa de matéria fresca (A) e seca (B) de caules e raízes de Cattleya bicolor após 180 dias de cultivo in vitro. Barras seguidas de letras diferentes apresentam variação significativa entre os tratamentos, segundo teste de Tukey $(\mathrm{P}<0,05)$. $(\mathrm{n}=40)$.

Figure 3. Effects of different culture media on average increase of shoot and root fresh matter (A) and on dry matter (B) of Cattleya bicolor after 180 days of in vitro culture. Vertical bars with different letters are significantly different, according to the Tukey test $(\mathrm{P}<$ 0.05). $(\mathrm{n}=40)$. 

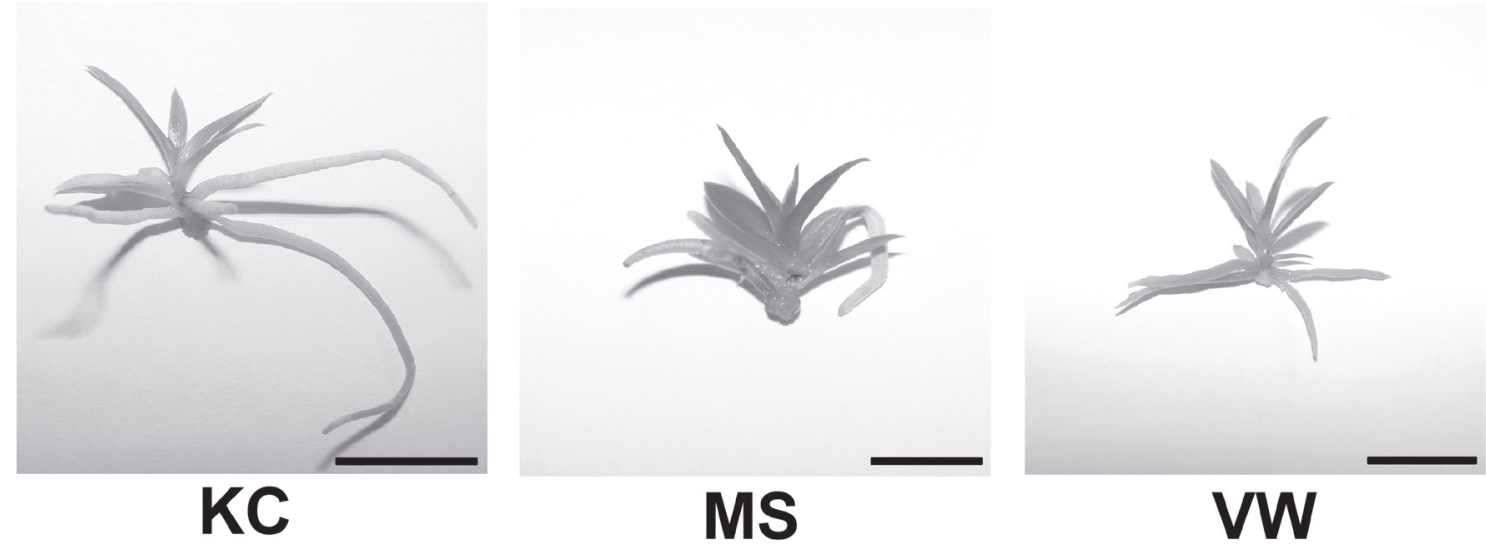

Figura 4. Morfologia geral das plantas de Cattleya bicolor cultivadas in vitro durante 180 dias nos meios KC, MS e VW. Escala $=1 \mathrm{~cm}$. Figure 4. General morphology of Cattleya bicolor plants cultivated in vitro for 180 days in the KC, MS and VW medium. Bars $=1 \mathrm{~cm}$.

importante analisar os meios de cultura utilizados sob o ponto de vista dos macronutrientes nitrogênio, fósforo e potássio. Embora na maioria dos meios de cultura o nitrogênio, sob a forma de amônia, esteja presente em menores concentrações que sob a forma de nitrato, alguns eventos morfogenéticos dependem da presença deste último. Por exemplo, de modo geral o crescimento radicial é inibido pela presença de amônia e promovido pelo nitrato (George et al. 2007). O comprimento das raízes de C. bicolor no meio VW (figura 1A), que apresenta a maior relação nitrato:amônia (tabela 1), reforça esta observação generalizada.

Em muitas espécies ambas as formas de nitrogênio (nitrato e amônia) são utilizadas na composição de diferentes meios de cultura. Para o crescimento in vitro de plântulas de algumas espécies de Cymbidium e Cattleya, o crescimento foi favorecido quando a composição de amônia era superior (Curtis \& Spoerl 1948). Contrariamente, para Bletilla striata, a presença de maior teor de nitrato favorecia o crescimento, quando este compreendia cerca de $90 \%$ da concentração de ânions no substrato (Ichihashi \& Yamashita 1977, Ichihashi 1978).

Possivelmente, C. bicolor apresenta capacidade de assimilar ambas as formas de nitrogênio, uma vez que pequenas diferenças foram observadas entre os meios MS e VW, com relação ao desenvolvimento das plântulas. O meio MS foi favorável para a formação de folhas (figura 2B), a massa de matéria fresca caulinar (figura 3A) e a massa de matéria seca radicial (figura 3B). É importante salientar que esse meio possui a maior concentração total de nitrogênio e a maior concentração relativa de nitrato em relação à amônia (tabela 1). $\mathrm{O}$ meio VW foi o mais eficaz para o crescimento caulinar (figura 2B), para o acúmulo de massa de matéria fresca radicial (figura 3A) e para o acúmulo de massa de matéria seca caulinar (figura 3B); ele contém a menor concentração total de nitrogênio $(12,77 \mathrm{mM})$ e a maior concentração relativa de amônia em relação ao nitrato $(1,46)$ (tabela 1), dentre os meios de cultura testados. A figura 4 apresenta plantas após 180 dias de cultivo nos diferentes meios de cultura.

Outro fator que deve ser considerado, é que a provável concentração insuficiente de fosfato no meio MS, conforme as opiniões de MacCarthy et al. (1980) e Bister-Miel et al. (1985) deferidas em relação ao cultivo in vitro de Carmine pratensis e Catharanthus roseus, respectivamente, não foi limitante para $C$. bicolor, provavelmente devido ao crescimento mais lento desta espécie de orquídeas em relação àquelas herbáceas estudadas pelos referidos autores.

A inibição no acúmulo de massa de matéria fresca e de matéria seca em caules e raízes de C. bicolor observado no meio $\mathrm{KC}$ (figura $3^{\mathrm{a}}, \mathrm{B}$ ) poderia ser resultante da reduzida concentração de potássio neste meio de cultura (tabela 1), pois Lavee \& Hoffman (1971) verificaram em cultura de calos de macieira que concentrações de 1,4 mM eram insuficientes para o crescimento vigoroso deste material. 
Com base nos resultados obtidos neste trabalho, recomenda-se a utilização do meio VW para a germinação das sementes e o crescimento inicial de Cattleya bicolor. Posteriormente, antes da fase de aclimatização, é interessante a transferência das plântulas para o meio MS ou VW, uma vez que eles promovem maior crescimento. Dessa forma, por volta de 360 dias após a semeadura, as novas plantas estariam melhor preparadas para responder as fortes mudanças impostas pela transferência para o ambiente ex-vitro.

\section{Agradecimentos}

Agradecemos ao Conselho Nacional de Desenvolvimento Científico e Tecnológico (CNPq) pelo apoio financeiro por meio de bolsa individual de Iniciação à Pesquisa do Programa Institucional de Bolsas de Iniciação Científica - PIBIC, concedida à Vanessa de Almeida.

\section{Literatura citada}

Andrade, S.R.M. 2002. Princípios da cultura de tecidos vegetais. Embrapa Cerrado. Documentos 58. Planaltina, DF, pp. 1-16.

Bister-Miel, F., Guignard, J.L., Bury, M. \& Agier, C. 1985 Glutamine as an active component of casein hydrolysate: its balancing effect on plant cells cultured in phosphorus deficient medium. Plant Cell Reports 4: 161-163.

Barros, F. 2007. A família Orchidaceae na flora do estado de São Paulo e suas espécies ameaçadas. In: M.C.H. Mamede, V.C. Souza, J. Prado, M.G.L. Wanderley, F. Barros \& J.G. Rando. (org.). Livro vermelho das espécies vegetais ameaçadas de extinção no estado de São Paulo. Secretaria do Meio Ambiente de São Paulo/Instituto de Botânica, São Paulo, pp. 47-52.

Braem, G.J. 1984. Cattleya: The Brazilian bifoliate cattleyas. Kurt Schmersow, Hiedesheim.

Curtis, J.T. \& Spoerl, E. 1948. Studies on the nitrogen nutrition of orchid embryos. II. Comparative utilization of nitrate and ammonium nitrogen. American Orchid Society Bulletin 17: 111-114.

Dutra, D., Johnson, T.R., Kauth, P.J., Stewart, S.L., Kane, M.E. \& Richardson, L. 2008. Asymbiotic seed germination, in vitro seedling development, and greenhouse acclimatization of the threatened terrestrial orchid Bletia purpurea. Plant Cell Tissue and Organ Culture 94: 11-21.
Dutra, D., Kane, M.E. \& Richardson, L. 2009. Asymbiotic seed germination and in vitro seedling development of Cyrtopodium punctatum: a propagation protocol for an endangered Florida native orchid. Plant Cell Tissue Organ Culture 96: 235-243.

Ferreira, W.M. 2003. Comportamento organogenético de meristemas caulinares de Dendrobium Second Love (Orchidaceae) in vitro. Tese de Doutorado, Universidade de São Paulo, São Paulo.

Ferreira, W.M. \& Suzuki, R.M. 2008. O cultivo in vitro de orquídeas como alternativa para a preservação de espécies nativas ameaçadas de extinção. In: M.I.B. Loiola, I.G. Baseia \& J.E. Lichston (orgs.). Atualidades, desafios e perspectiva da botânica no Brasil. Imagem Gráfica, Natal, pp. 67-68.

Gamborg, O.L. 1970 The effects of amino acids and ammonium on the growth of plant cells in suspension culture. Plant Physiology 45: 372-375.

George, E.F., Hall, M.A. \& De Klerk, G.J. 1997. Plant propagation by tissue culture v. $1.3 \mathrm{ed}$. The Background. Springer.

Ichihashi, S. \& Yamashita, M. 1977. Studies on the media for orchid seed germination part 1: the effects of balances inside each cation and anion group for the germination and seedling development of Bletilla striata seeds. Journal of the Japanese Society for Horticultural Science 45: 407-13.

Ichihashi, S. 1978. Studies on the media for orchid seed germination. II. The effects of anionic and cationic combinations relevant to seedling populations and culture periods on the growth of Bletilla striata seedlings. Journal of Japanese Society Horticultural Science 46: 521-529.

Kauth, P.J., Vendrame, W.A. \& Kane, M.E. 2006. In vitro seed culture and seedling development of Calopogon tuberosus. Plant Cell Tissue and Organ Culture 85: 91-102.

Knudson, L. 1946. A new nutrient solution for germination of orchid seeds. American Orchid Society Bulletin 15: 214-217.

Kohl, H.C. 1962. Notes on the development of Cymbidium from seed to plantlet. American Orchid Society Bulletin 31: 117-120.

Lavee, S. \& Hoffman, M. 1971. The effect of potassium ions on peroxidase activity and its isoenzyme composition as related to apple callus growth in vitro. Botanical Gazette 132: 232-237. 
MacCarthy, J.J., Ratcliffe, D. \& Street, H.E. 1980

The effect of nutrient composition on the growth cycle of Catharanthus roseus $\mathrm{G}$. Don cells grown in batch culture. Journal Experimental Botany 31: 1315-1325.

Murashige, T. \& Skoog, F.A. 1962. A Revised medium for rapid growth and bioassays with tobacco tissue culture. Physiologia Plantarum 15: 473-497.

Raghavan, V. \& Torrey, J.G. 1964. Inorganic nitrogen nutrition of the seedlings of the orchid, Cattleya. American Journal of Botany 51: 264274.

Rasmussen, H.N. 1995. Terrestrial orchids from seed to mycotrophic plant. Cambridge University Press.

Rego-Oliveira, L. \& Faria, R.T. 2005. In vitro propagation of Brazilian orchids using traditional culture media and comercial fertilizers formulation. Acta Scientiarum 1: 1-5.

Shiau, Y.J., Nalawade, S.M., Hsai, C.N. \& Tsay, H.S. 2005. Propagation of Haemaria discolor via in vitro seed germination. Biologia Plantarum 49: 341-346.
Stewart, S.L. \& Kane, M.E. 2006. Asymbiotic seed germination and in vitro seedling development of Habenaria macroceratitis (Orchidaceae) a rare Florida terrestrial orchid. Plant Cell Tissue and Organ Culture 86: 147-158.

Stoutamire, W.P. 1964. Seeds and seedlings of native orchids. Michigan Botanist 3: 107-119.

Suzuki, R.M. \& Ferreira, W.M. 2007. Introdução às técnicas de micropropagação de orquídeas. In: L.M. Barbosa \& N.A. Santos-Jr, (orgs.). A Botânica no Brasil: pesquisa, ensino e políticas públicas ambientais. 1 ed. Imprensa Oficial do Estado, São Paulo, pp. 655-659.

Suzuki, R.M., Moreira, V.C., Nakabashi, M. \& Ferreira, W.M. 2009. Estudo da germinação e crescimento in vitro de Hadrolaelia tenebrosa (Rolfe) Chiron \& V.P. Castro (Orchidaceae), uma espécie da flora brasileira ameaçada de extinção. Hoehnea 36: 657-666.

Vacin, E.F. \& Went, F.W. 1949. Some pH in nutrient solutions. Botanical Gazette 110: 605-617.

Van Waes, J.M. \& Debergh, P.C. 1986. In vitro germination of some Western European orchids. Physiologia Plantarum 67: 253-261. 